ISAHP 1996, Vancouver, Canada, July 12-15, 1996

\title{
RESOURCE ALLOCATION TO ROAD SAFETY AND THE ANALYTICNETWORK PROCESS
}

\author{
Simin Jalali R. Rabbani and Soheil Rahnemay Rabbani \\ Civil Engineering Department \\ Center of Science and Technology \\ Federal University of Paraiba \\ simin@dsc.ufpb.br/rabbani@dsc.ufpb.br
}

\begin{abstract}
This paper contains an application of the Analytic Network Process to resource allocation for road safety in Brazil. Three separate models are considered: one for benefits, one for costs and a third for risks. The conclusion of this study is based on the benefits/costs $\mathrm{x}$ risks is that in the long run education and training are the most influential factors to reduce transit accidents.
\end{abstract}

\section{Introduction}

Thus far, the problems used in the AHP applications have been modelled hierarchically, from higher to lower levels or conversely. Real world problems involve interdependencies between elements. That is, the elements in a lower level might influence one or more elements in a higher level. Most decisions need to be free from assumptions of independence to be faithful to the complex problems from which they rise. Saaty has developed a systemic methodology for structuring and solving problems involving general types of dependence between criteria and alternatives, criteria and other criteria, and alternatives and alternatives. It is based on the feedback system framework of the Analytic Hierarchy Process of which a hierarchy is a special case. This methodology is called the Analytic Network Process, ANP. Prediction of future needs in transportation often requires feedback because of the strong interactions between transportation and other societal activities and between present and future needs.

In the ANP, the problem is defined by its principal components. Each component, in turn, is defined by a set of homogeneous elements related through criteria that govern the influences in the system. These criteria, called control criteria, belong to a hierarchy known as the control hierarchy. The components of the system interact differently with each other according to each control criterion. Thus, we must derive limiting priorities for the influences of each control criterion. The cause and effect relationships between the elements and components are represented by links in the model. These elements and components are then pairwise compared in the usual way to derive a priority vector for each relationship. Using these priorities, a supermatrix which contains blocks of interaction among components is formed. The limiting 
priorities of the supermatrix are computed to derive relative weights of the elements of the system. For more details see Saaty (1994).

In this work we show the applicability of the Analytic Network Process to the problem of improving road safety. The goal is to determine how to save lives and obtain the necessary mobility through improvements in road transportation. A desirable solution must reduce the risks and costs and provide sufficient mobility. The major policy question to be resolved is to what extent and in what ways are resources to be expended on road safety.

Such a network approach makes it possible to represent and analyse interactions and to synthesize their mutual effects in a single logical procedure. The Analytic Network Process is applied to analyse the relative effectiveness of road safety measures in each component of road safety; vehicle, road, driver, community and government. The efforts directed toward improving road safety were limited by economic and social considerations. In this study, long term cause-effect relationships between the components of the system will also be taken into consideration.

\section{Model Structuring}

In this application, the network structure requires the identification of the principal clusters of the system as well as the relationships among these clusters. This approach provides the means. to represent and analyse interactions and also to synthesize their mutual effects through a single logical procedure.

Setting operational goals is always a top policy matter and an evaluation of alternative goals is the first and major policy decision. The establishment of two goals, reducing fatalities and, injuries and limiting the expenditure of private and public funds, is essential to a rational process of improving road safety. Since there are limits on resources as well as the existence of other critical community problems in health, welfare, and safety, a basis is needed for comparing the effectiveness of different programs. After the benefits have been thoroughly assessed, the marginal programs be eliminated. What is most critically needed is a reliable estimate of the results that can be achieved within a specified time for a given level of resources. The setting of goals or the limiting of expenditures, therefore, is a political decision related to achieving the best balance in meeting the total needs of a community or the nation. Due to its importance, we have defined improving road safety as the overall goal for this problem. 
To achieve maximum road safety, or lowest risk, we aim to attain the minimum level of risk for a given mobility by using the available resources in the most effective manner. Mobility is used a general term that refers to the individual needs and desires that are furthered by the transport of people and freight. The basic assumption is that some minimum level of mobility is essential to human survival. It is further assumed that only up to a certain point will an increase in mobility increase man's ability to fulfill his aspirations. The combined characteristics of this system will have a greater effect on the frequency of highway accidents than will any single component. A network system permits many dimensions of the problem to be decomposed into benefits, costs and risks models for the evaluation of alternative courses of action. Lower risk, lowest cost, with highest benefits in terms of mobility is the simplest description of the best solution. In this model there are three assumptions: (1) mobility, which significantly influences the quality of life is necessary, (2) some risk must be incurred in order to achieve mobility, and (3) the available resources, such as finances and time, are limited.

Three separate models were designed, one for benefits, one for costs, and a third for risks. We grouped all of the control criteria for the benefits with a single criterion called benefits, and did the same for costs and for risks. The benefit model indicates the alternative with the most benefit. Similarly, the risks and cost models indicate the ones that are most costly and risky, respectively.

$$
\therefore \%
$$

Benefits Model: In this model, the benefits derived from road safety are defined as the advantages gained by making' a given decision from social and economic standpoints. Economic benefits refer to a decision's positive effect on the availability of appropriate service and quick travel for the specified population and economic region. In the benefits model, although emphasis has been placed on the economic losses resulting from road accidents, the problem is dominated by humanistic concerns. For example, if a very favorable economic return were shoẅn to result from highway safety expenditures, but thousands of people were being killed eviery year, the public is not likely to approve the expenditures.

Social benefits are viewed in terms of their contribution to individuals and to society as a whole. Personal benefits are viewwed in terms of their contribution to individuals. The latter benefits include comfort in traveling and"easy accessibility, while benefits to society include safety and reliability, improved communication, and decreases in congestion and travel time.

,

$\dot{C}$ Costs Model: Similar to the benefits model, the costs model examines the decision situation from both the economic and social standpoints. The economic costs include capital costs, operating and maintenance costs, and economic consequences of changing the existing system. The social costs represent costs to 
society and may be interpreted as the increased disnuption due to congestion and the changes in lifestyle often referred to as "cost of modernization". For instance, if traveling becomes easier, people's mobility will increase and local workers in one region may face the possibility of being replaced by better skilled, more experienced workers who come in from neighboring regions. Finally, the contribution of the increase of automobile production to the environmental problems such as air and water pollution, and the disruption of the ecosystem were also considered in the model.

Risks Model: An accident is a breakdown or failure of the transport system to safely get people and goods from one point to another. From this perspective, the problem is one of reducing the risk in the system. This distinction is significant because a reduction in risk can be more effectively treated than can the elimination of "causes".

Risk can be defined as the probability of harm. The degree of risk associated with an activity is the probability of harm multiplied by the severity of harm. The distinctive feature of this definition is that the degree of risk is qualitatively determinable. However, safety is quantitative in nature. To say that an activity is "safe" is to make a judgment that the degree of risk associated with that activity is acceptable. Risks are measured only when they are weighed on a balance of social values where safety can be judged. An activity is safe if its attendant risks are judged to be acceptable.

To weigh alternatives we design the control hierarchy from economic and social standpoints, the major factors that determine resource allocation to the road safety problem. The relative importance of these two factors is obtained and included in the control hierarchy shown in Figure 1. 


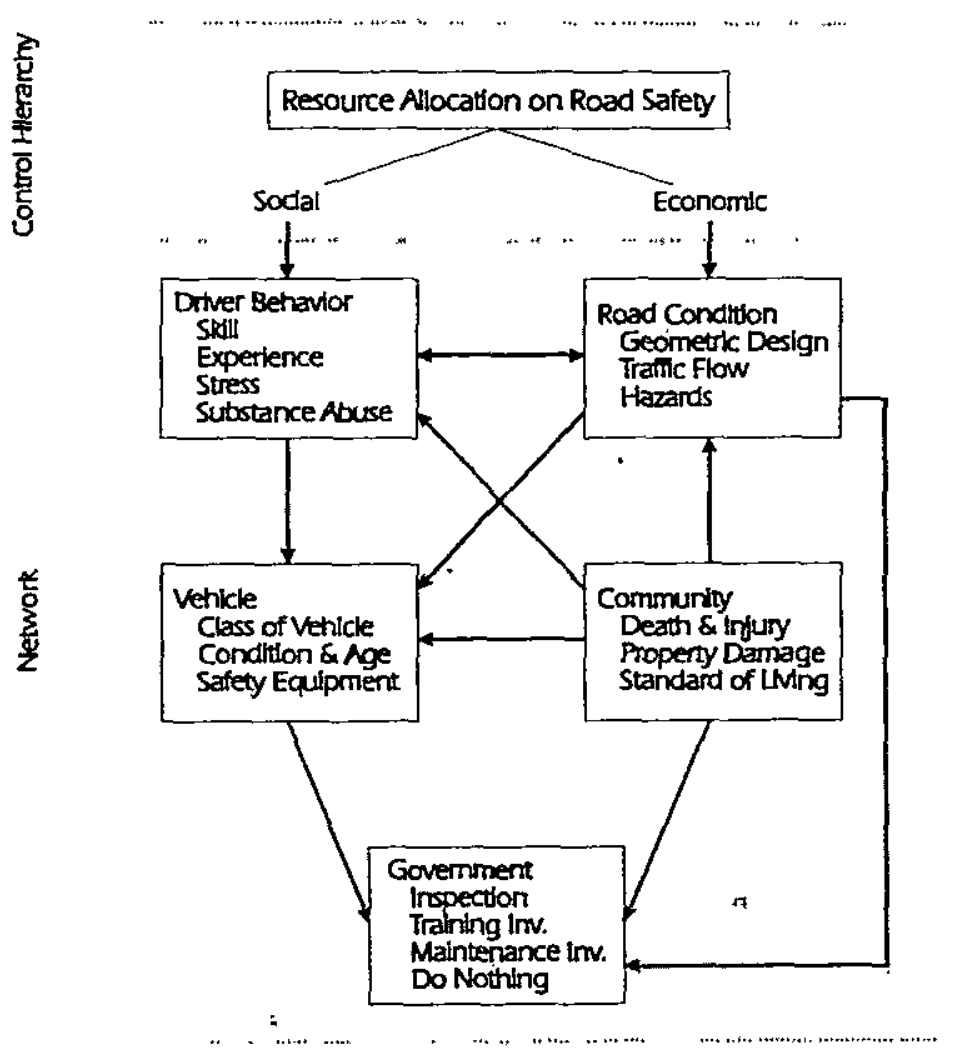

Figure 1. Network Presentation of Resource Allocationon Road Safety

Social factor - For the issue under investigation, social impact is the most important factor because the loss of life is essentially a social problem. However, a solution can only be achieved through a sound technological approach. That is, we must note that for the problem of road safety a reduction in loss of life is as complex as the problems inherent to health and welfare.

Economic factor - Although analyses based on economic returns are not of great assistance in dealing with values such as the preservation of life, we must not ignore its importance. Even though discussions and debate center on questions of safer vehicles, safer highways, better driver behavior, better medical services, or improved law enforcement, the time comes when effects on mobility cannot be avoided. Even though cost is viewed as irrelevant where preservation of life is concerned, expense must ultimately be considered because resources are limited. Safety must be viewed within a realistic understanding of its role in the multiple objectives of highway transportation. 


\section{Network Components and Elements}

The set of relevant components of the road safety model, that is, the vehicle, human behavior, the road environment, community and government were defined as clusters with their respective elements as follows:

Vehicle- Vehicle performance includes vehicle controls such as brakes, steering, and lights, named in the model as condition and age. Vehicle design characteristics involve factors related to design such as springs, anti-sway bars, mass distribution, seating arrangements, and others such as safety equipment, as well as the maintenance of the vehicle, called safety equipment in the model. Another element under consideration is the type of vehicle such as a truck, private car, or motorcycle defined as the class of vehicle.

Driver Behavior-Although the behavior of the pedestrian in normal traffic can and should be studied, much more research has been conducted so far on the effect of behavioral factors of the driver on accidents. Human elements such as age and risk-taking behavior, the effects of stress on one's physical and mental state, alcohol and drug consumption, skill and experience including pre-occupation, perception and comprehension were also considered.

Road Conditions- The elements of this component include traffic flow of all other vehicles in the local environment, road hazards including highway debris and blocked traffic lanes, and geometric design including width, surface, signs, and road maintenance.

Government Policies - Public policies include the following measures: vehicle inspection, enforcement, training and education, construction and maintenance of roads, and doing nothing. Resource allocation is a key role of top management and requires control of the total operation through the assignment of funds to programs. Each policy action is associated with a list of related costs. For example, a partial list of costs associated with inspection includes vehicle repairs that are required as a result of the inspection process, additional repairs due to the inspection process, and direct payments and value of time for (re)inspection.

Community-Improving road safety brings forth social benefits by decreasing damage to property, death and injury to individuals, and pain and suffering to society as a whole. 


\section{Prioritization and Sysnthesesof the Weights}

In order to understand the net causes and effects in this system as well as how to control them we need to set priorities. In developing judgments, three influences were considered, the annual increase in number of fatalities that would occur if no changes were introduced, the redundancy or actions that have a duplicative effect, and the limited effects or measures that can influence only a portion of the accidents. The priority eigenvectors of the elements are obtained by pairwise comparisons of the elements in a component with respect to the elements in another component as well as with elements within the component.

Briefly, the system prioritization approach begins with a supermatrix of blocks of interaction among cormponents. Each column of a block is a vector of priorities which represents the impact of a component on an element in the system. These vectors are obtained from individual matrices of paired comparisons: one set for comparing components in terms of other components by answering the question "Given a certain component, what is the relative influence of a pair of components, with respect to a control criterion".. The other set for comparing the elements within a component or between different components, by answering the question "Given a certain element, what is the relative influence of each pair of elements with respect to a control criterion on that element?"

We ask these questions in order to determine the importance of each factor relative to the others. For example, within the social context in the benefits model and comparing two components given another component, we set the question: "Which component, vehicle or road, contributes the most to improving driver behavior and by how much?" In the costs model, when we compare the effect of two elements within the same cluster and with respect to an element that belongs to another component, we ask: "Which of the elements, traffic flow or road design contribute more and how much more to the stress of the driver?" Finally, in the risk model we have formulated a set of questions such as "Between the elements, class of vehicle and condition and age, which one creates a greater risk for causing death and injury?"

The supermatrix corresponding to the interaction between the components of the benefits model plays a fundamental role in the subsequent development of priorities for the elements of the system. The components of the system, and hence also the elements in these components, can interact along more than a single path. One component can, for example, interact indirectly with another by first influencing an intermediate component. The priorities of influence which flow from one component to others may be measured over all of the paths and cycles which connect them. The principal discussion in this paper 
focuses on deriving limiting or steady state priorities from the supermatrix. It must first be reduced to a matrix in which the columns sum to unity. Such a matrix is known as a column stochastic or simply, a stochastic matrix. The limiting results of the supermatrices corresponding to interaction between the components of the system for the benefits and costs models are displayed in Table 1.

Table 1. Global Synthesized Priorities obtained from Benefits and Costs Models

$\begin{array}{lll}\text { Clusters } & \text { Benefit } & \text { Cost } \\ \text { Driver Behavior: } & & \\ \text { Skill } & 0.0712 & 0.0075 \\ \text { Stress } & 0.0265 & 0.0692 \\ \text { Substance Abuse } & 0.0128 & 0.0538 \\ \text { Age \& Experience } & 0.0764 & 0.0069 \\ \text { Road Condition: } & & \\ \text { Geometric Design } & 0.0615 & 0.0780 \\ \text { Traffic Flow } & 0.0553 & 0.0817 \\ \text { Hazards } & 0.0392 & 0.0756 \\ \text { Vehicle: } & & \\ \text { Class of Vehicle } & 0.0163 & 0.0214 \\ \text { Condition \& Age } & 0.0142 & 0.0372 \\ \text { Safety Equipment } & 0.0043 & 0.0132 \\ \text { Community: } & & \\ \text { Death \& Injury* } & 0.2138 & 0.3044 \\ \text { Damage to Property } & 0.1369 & 0.1008 \\ \text { Standard of Living } & 0.1336 & 0.0663 \\ \text { Government } & & \\ \text { Training \& Education } & 0.0505 & 0.0149 \\ \text { Enforcement } & 0.0451 & 0.0198 \\ \text { Inspection } & 0.0103 & 0.0102 \\ \text { Construction \& Maintenance } & 0.0253 & 0.0210 \\ \text { Do Nothing } & 0.0066 & 0.0180\end{array}$

- Death \& Injury in cost model is equivalent to Health \& Welfare in benefits model

\section{Discussion}

In reality, an accident is a failure of the road transportation system to get people and goods from one point to another with a reasonable degree of safety. All accidents, for practical purposes, have more than one contributing element. Attempts to determine causes or unsafe conditions are typically based on a simple cause-and-effect assumption. 
The relative priorities of the clusters with respect to each cluster are displayed in Table 2. The following is a brief discussion of the results.

Benefits Model-The resulting priorities indicate that from the driver's standpoint, other drivers' behavior exerts the most influence $(0.3757)$, followed by vehicle $(0.2331)$, and road $(0.1485)$. Road conditions are affected the most by economic factors ( 0.3137$)$, secondly by the government $(0.2845)$, and lastly by social factors $(0.2369)$. On the other hand, for the government, social factors $(0.3642)$, and economic factors (0.3049) are the most important elements followed by road conditions $(0.1643)$ and driver behavior (0.1017). The vehicle is most affected by road conditions $(0.4322)$, followed by driver behavior $(0.2490)$, and government policies $(0.1757)$. From the social standpoint, economic factors $(0.4351)$ most influence the welfare of the community under investigation, followed by driver (0.2527). From an economic standpoint, economic factors $(0.3301)$ exert the highest influence, followed by government $(0.2781)$, social $(0.1565)$, and road (0.1169) as the most influential elements.

Table 2. Relative Priorities of the Clusters with Respect to Each Cluster

$\begin{array}{llccc} & & \text { BenefitModel } & \begin{array}{c}\text { Cost } \\ \text { Model }\end{array} & \text { Risk Model } \\ & \text { Government } & 0.0981 & 0.0369 & \\ \text { Driver } & \text { Vehicle } & 0.2331 & 0.2977 & \\ & \text { Social } & 0.0622 & 0.1068 & \\ & \text { Economic } & 0.0824 & 0.0492 & \\ & \text { Driver } & 0.3757 & 0.3341 & \\ \text { Road } & \text { Road } & 0.1485 & 0.1753 & \\ & \text { Government } & 0.2845 & 0.0315 & \\ & \text { Vehicle } & 0.0541 & 0.3994 & \\ & \text { Social } & 0.2369 & 0.0600 & \\ & \text { Economic } & 0.3137 & 0.2559 & \\ \text { Government } & \text { Driver } & 0.0821 & 0.1059 & \\ & \text { Road } & 0.0287 & 0.1473 & \\ & \text { Vehicle } & 0.0650 & 0.0987 & \\ & \text { Social } & 0.3642 & 0.2845 & \\ & \text { Economic } & 0.3049 & 0.3824 & \\ & \text { Driver } & 0.1017 & 0.0486 & \\ & \text { Road } & 0.1643 & 0.1859 & \\ & \text { Gohicle } & 0.1757 & 0.1014 & 0.5000 \\ & \text { Social } & 0.0481 & 0.0970 & \\ & \text { Economic } & 0.0951 & 0.1194 & \\ & \text { Driver } & 0.2490 & 0.2168 & \\ & \text { Road } & 0.4322 & 0.4654 & \end{array}$




$\begin{array}{lllll} & \text { Government } & 0.1261 & 0.1161 & 0.1335 \\ \text { Social } & \text { Social } & 0.0352 & 0.0377 & 0.3445 \\ & \text { Economic } & 0.4351 & 0.5270 & 0.3246 \\ & \text { Driver } & 0.2527 & 0.0710 & \\ & \text { Road } & 0.1509 & 0.2482 & \\ & \text { Government } & 0.2781 & 0.2368 & 0.3816 \\ & \text { Vehicle } & 0.0716 & 0.0563 & 0.0768 \\ \text { Economic } & \text { Social } & 0.1565 & 0.1490 & 0.5415 \\ & \text { Economic } & 0.3301 & 0.3577 & \\ & \text { Driver } & 0.0467 & 0.0601 & \\ & \text { Road } & 0.1169 & 0.1400 & \\ & \text { Economic } & & & 0.0866 \\ & \text { Social } & & & 0.4558 \\ & \text { Vehicle } & & & 0.0306 \\ & \text { Government } & & & 0.1981 \\ & \text { Political } & & & \end{array}$

Among the alternative courses of action (Table 3 ), education and training $(0.3664)$ received the highest priority, followed by enforcement $(0.3272)$, road maintenance $(0.1637)$, and inspection $(0.0747)$. The do nothing alternative gained the least priority $(0.0482)$, presumably because the present situation is highly critical to the health and welfare of the society.

Costs Model - In this model we considered generalized costs, including out of pocket expenses, loss of property, as well as social and economic losses incurred by the community.

Road construction and maintenance $(0.2504)$ yields the highest priority, followed by enforcement $(0.2365)$, doing nothing $(0.2142)$, and training $(0.1776)$. It should be noted that training provides the least cost, because it has a significant influence on improving safety as lessening death and injury and damage to property. Road construction and maintenance yields the highest cost because of the relatively high investment necessary for this alternative.

Final global synthesized results obtained from the costs model indicate that economic factors, such as activity level and infrastructure of the system, are important elements that must be examined by the authorities. Furthermore, the cost of inspection $(0.1220)$ is the lowest, followed by training $(0.1776)$, do nothing $(0.2142)$, enforcement $(0.2365)$, and maintenance $(0.2504)$.

Risks Model- The results from the risks model indicate that the alternative do nothing $(0.4594)$ yields the highest risk to society, followed distantly by enforcement $(0.1592)$, maintenance $(0.1372)$, and inspection (0.1026). Political elements play important roles in the risks model. Popularity of the government 
$(0.1833)$ and the effects on reelection $(0.1296)$ were assigned the highest priority in the risks model, suggesting that these factors may influence the scheduling of the investments on roads and maintenance.

Road safety programs must be oriented toward minimizing risk for a given mobility level by using the available resources in the most effective manner. Using three models, benefits, costs, and risks, allows us to structure the problem from a systems perspective. This broad approach ensures greater effectiveness through the long term.

In view of the limited financial resources available for road safety, it is important to devise policies that allocate them to the most appropriate activities. Achieving a good match between an activity and its target requires a sound understanding of the nature of accidents and the interaction among the factors related to the people involved, the vehicles and the road environment.

Road safety measures are administered by a variety of agencies including government departments, national organizations and professional bodies, so there is a need to evaluate the "institutional effect" and make allowance for it when designing integrated policies. The synthesized dependence priorities of the components derived from these benefits, costs and risks, as well as the ratio: benefits/(cost $x$ risk) appears in Table 2.

When we view safety from a systems perspective, it becomes evident that perfect administration or law enforcement does not guarantee safety. The objective is met through a combination of factors that produce the safest conditions with the least risk for the mobility level desired and with the resources available. This distinction is critically important because it underscores the possibility of suboptimization by spending too much on one component and not enough on another.

Table 3. Final Priorities Obtained from Benefit, Cost, and Risk Models

$\begin{array}{lcccc}\text { Alternative } & \begin{array}{c}\text { Benefit } \\ \text { (B) }\end{array} & \text { Cost (C) } & \begin{array}{c}\text { Risk } \\ \text { (R) }\end{array} & \begin{array}{c}\text { Benefit/ } \\ \text { (CostxRisk) }\end{array} \\ \text { Training \& Education } & 0.3664 & 0.1776 & 0.1418 & 14.5491 \\ \text { Enforcement } & 0.3272 & 0.2365 & 0.1592 & 8.6904 \\ \text { Inspection } & 0.0747 & 0.1220 & 0.1026 & 5.9678 \\ \text { Construction \& } & 0.1837 & 0.2504 & 0.1372 & 5.3471 \\ \text { Maintenance } & 0.0482 & 0.2365 & 0.4594 & 0.4898 \\ \text { Do Nothing } & & & & \end{array}$

The process which determines long-range strategic decisions is more complicated than it is for day-to-day 
tactical decisions. In this application of ANP we have addressed a wider range and less quantifiable set of criteria than what is normally encountered in short-range decisions. Since long-range planning requires actions now but the major impact is long term, we have considered feedback to evaluate different government policies.

In summary, the result of the benefits model indicates that among alternative policies of the government, training and education provides the highest benefit; construction and maintenance yields the highest cost, and the do nothing policy exerts the highest risk to the community. In this model, the result of the ratio benefits/(costs $\mathrm{x}$ risks) indicate that training and education requires the highest priority in the financial resource allocation of the government to provide safety on roads in Brazil.

\section{BIBLIOGRAPHY}

1. OECD-Organization for Economic Cooperation and Development, 1986, "Road Safety Research: A Synthesis," Road Transport Research, Paris.

2. OECD-Organization for Economic Cooperation and Development, 1981, "Methods for Evaluating Road Safety Measures, " Road Transport Research, Paris.

3. OECD-Organization for Economic Cooperation and Development, 1970, "Driver Behavior, "Road Transport Research, Paris.

4. OECD-Organization for Economic Cooperation and Development, 1974, "Research on Traffic Law Enforcement," Road Transport Research, Paris.

5. OECD-Organization for Economic Cooperation and Development, 1975, "Young Driver Accidents," Road Transport Research, Paris.

6. OECD-Organization for Economic Cooperation and Development, 1970, "Pedestrian Safety," Road Transport Research, Paris.

7. OECD-Organization for Economic Cooperation and Development, 1990, "Integrated Traffic Safety Management in Urban Areas," Road Transport Research, Paris.

8. OECD-Organization for Economic Cooperation and Development, 1985, "Traffic Safety of Elderly Road Users," Road Transport Research, Paris.

9. OECD-Organization for Economic Cooperation and Development, 1988, "Road Accidents: On-Site Investigations, "Road Transport Research, Paris.

10. OECD-Organization for Economic Cooperation and Development, 1978, "Safety of Two-Wheelers," Road Transport Research, Paris.

11. OECD-Organization for Economic Cooperation and Development, 1971, "Road Safety Campaigns: 
Design and Evaluation, " Road Transport Research, Paris.

12. OECD-Organization for Economic Cooperation and Development, 1972, "Speed Limits Outside BuiltUp Areas," Road Transport Research, Paris.

13. OECD-Organization for Economic Cooperation and Development, 1978, "New Research on the Role of Alcohol and Drugs in Road Accidents," Road Transport Research, Paris.

14. Tarski, I., 1987, The Time Factor in Transportation Processes, Elsevier, Amsterdam.

15. Saaty, T.L., 1994a, Fundamentals of Decision Making and Priority Theory with the Analytic Hierarchy Process, RWS Publications, Pittsburgh, PA.

16. Saaty, T.L., 1994b, Decision Making in Economic, Political, Social and Technological Environments: The Analytic Hierarchy Process, RWS Publications, Pittsburgh, PA.

17. Evans L., 1991, Traffic Safety and The Driver, Van Nostrand Reinhold, New York.

18. Baker, R.F., 1971, The Highway Risk Problem: Policy Issues in Highway Safety, Wiley-Interscience, New York.

19. Saaty, T.L., 1995, Expert Choice for Feedback Modelling-ECNET, Software, Pittsburgh, PA. 